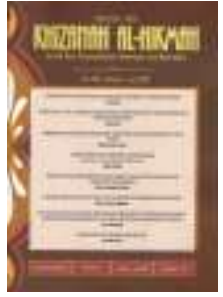

\title{
PENERAPAN EPRINT SEBAGAI REPOSITORI INSTITUSI PADA PERPUSTAKAAN UNIVERSITAS MUHAMMADIYAH MALANG
}

\author{
Gani Nur Pramudyo*, Zurika Sintia Putri, Ismail Alim Prayogi*, \\ Anggayuh Mukti Sari*, Sri Widianah*, Yuli Trisnawati*
}

Pengutipan: Pramudyo, G. N., Putri, Z. S., Prayogi, I. A., Sari, A. M., Widianah, S., dan Trisnawati, Y. (2018). Penerapan eprint sebagai repositori institusi pada Perpustakaan Universitas Muhammadiyah Malang. Khizanah al-Hikmah : Jurnal Ilmu Perpustakaan, Informasi, dan Kearsipan, 6(1), 12-19.

DOI: $10.24252 /$ kah.v6a1a2

\section{*Universitas Brawijaya}

gani_nurp@yahoo.com (email korespendansi untuk semua penulis)

\section{ABSTRAK}

Penelitian ini bertujuan untuk mengetahui bagaimana penerapan perangkat lunak repositori intitusi eprint di Perpustakaan Universitas Muhammadiyah Malang (Perpustakaan UMM) serta untuk mengetahui faktor pendukung dan penghambat dalam penerapannya. Penelitian ini dilakukan dengan menggunakan metode studi kasus dengan pendekatan kualitatif. Pengumpulan data dilakukan dengan observasi partisipasi pasif, wawancara dan dokumen. Penelitian ini menunjukkan bahwa Perpustakaan UMM menggunakan dua repositori intitusi yaitu ganesha digital library (GDL) dan Eprint. GDL berisi lokal konten UMM dapat diakses secara fullteks di jaringan lokal perpustakaan, namun tidak masuk pemeringkatan webometric repositori.Sedangkan Eprint digunakan untuk menunjang dan mendongkrak pemeringkatan repository webometric UMM dan hanya berisi deskripsi bibliografi, abstrak dan BAB 1 -3.

Kata kunci: Repositori institusi; perangkat lunak Eprint

\section{ABSTRACT}

This study aims to find out how the application of intensive repository software in the Library University of Muhammadiyah Malang (UMM Library) and to know the supporting and inhibiting factors in its application. This research is a case study. Data collection are throughout by passive participation observation, interview and document. This research shows that UMM Library uses two intitusional repositories ganesha digital library (GDL) and Eprint. GDL contains local content of UMM can be accessed fulltext in the local network of libraries, but not in webometric repository ranking. While Eprint is used to support and boost the UMM webometric rating repository and contains only bibliographic, abstract and chapter 1-3 descriptions.

Keywords: Institutional repository; Eprint software

\section{PENDAHULUAN}

Tata kelola informasi yang baik merupakan wujud dan upaya yang dilakukan oleh setiap organisasi atau intitusi yang mengelola, menyimpan, menemubalik, dan menyebarluaskan informasi. Salah satu organisasi yang mengelola informasi yaitu perpustakaan perguruan tinggi. Tren perpustakaan perguruan tinggi saat ini yaitu pengelolaan koleksi digital dalam sebuah repositori intitusi. Salah satu pendukungnnya yaitu perangkat lunak repositori intitusi. Di masing-masing perpustakaan perguruan tinggi di 
Indonesia telah menggunakan dan menerapkan perangkat lunak repositori intitusi yang berbeda. Penggunaan perangkat lunak repositori intitusi tersebut di beberapa perguruan tinggi ada yang berbayar, mengembangkan sendiri dan juga menggunakan perangkat lunak repositori intitusi open-source. Di perpustakaan perguruan tinggi Indonesia, perangkat lunak repositori intitusi open source saat ini yang banyak digunakan seperti GDL, Dspace dan Eprints.

Rodliyah (2016) menjelaskan, akhirakhir ini terdapat kecenderungan bahwa perpustakaan perguruan tinggi di Indonesia banyak yang menggunakan Eprints. Berdasarkan peringkat webometric repositori perguruan tinggi dalam skala dalam negeri (Indonesia) yang dilansir oleh website http:/ / repositories.webometrics.info/ memberikan gambaran perbandingan perangkat-perangkat lunak yang digunakan sebagai repositori institusi.

Tabel 1. Perbandingan jumlah pengguna perangkat lunak Eprint, Dspace, dan GDL versi webometrics di Indonesia

\begin{tabular}{|l|l|c|c|}
\hline No. & $\begin{array}{c}\text { Aplikasi/Perangkat } \\
\text { lunak }\end{array}$ & $\begin{array}{c}\text { Jumlah } \\
\text { Pengguna }\end{array}$ & $\mathbf{\%}$ \\
\hline 1. & Eprints & 34 & $57 \%$ \\
\hline 2. & Dspace & 8 & $13 \%$ \\
\hline 3. & GDL & 1 & $0,4 \%$ \\
\hline 4. & $\begin{array}{l}\text { Institutional } \\
\text { Development }\end{array}$ & 10 & $17 \%$ \\
\hline
\end{tabular}

Keterangan: dari 60 (enam puluh) perguruan tinggi di Indonesia, 57\% menggunakan Eprint sebagai perangkat lunak repositori institusi mereka.

Salah satu contoh penggunaan Eprint di perpustakaan perguruan tinggi di
Malang yakni di perpustakaan Universitas Muhammadiyah Malang (UMM). Perpustakaan UMM menggunakaan Eprint dalam mengelola konten yang dimiliki seperti tugas akhir dan karya ilmiah. Selain itu perpustakaan UMM memanfatkan Eprint untuk menaikkan peringkat repositori webometric.

Dari observasi awal, penerapan Eprint di perpustakaan UMM terdapat beberapa masalah yang dihadapi. Menurut $M$. Hafiz Ahyanoor selaku Staf ELSS (Electronic Library Support System) menjelaskan:

"Di Perpustakaan UMM terdapat pemisahan repositori intitusi yaitu antara GDL (ganesha digital Library) dan Eprint. GDL hanya dapat di akses di perpustakaan bersifat lokal dan berisi literatur kelabu yang dapat diakses secara fulltext, namun tidak terindeks di Webometric. Sedangkan Eprint dapat diakses secara online dan terindeks oleh pemeringkatan repositori webometric, namun hanya berisi judul dan abstrak tugas akhir". (Wawancara, 8 Juni 2017).

Pemisahan repositori intitusi ini terjadi karena masing-masing perangkat lunak repositori intitusi memiliki kelebihan dan kelemahan tersendiri, oleh karena itu perpustakaan mengupayakan untuk tetap memberikan pelayanan repositori intitusi yang baik kepada pemustaka dengan menjalankan kedua perangkat lunak tersebut. Masalah lainnya, seperti kurangnya sosialisasi yang dilakukan oleh pihak Perpustakaan UMM, sehingga menyebabkan pemustaka tidak tahu tentang keberadaan Eprints.

Selain itu terkait peran dan posisi perpustakaan UMM, dalam penerapan Eprint yang masih belum jelas. Hal ini diperkuat oleh hasil wawancara peneliti kepada Umi Chasanah, selaku humas 
Perpustakaan UMM yang menerangkan bahwa

"perpustakaan UMM hanya sebagai operator atau pengelolaan konten/informasi yang bertugas meng entri konten atau informasi berupa tugas akhir (skripsi, thesis, disertasi dan karya ilmiah lainya) di Eprint, sementara Lembaga Infokom yang bertugas mengembangkan dan mengelola sistem Eprint".

(Wawancara Rabu, 8 Maret 2017).

Perpustakaan seyogyanya bukan berperan sekunder atau sebagai operator dalam mengembangkan dan mengola repositori intitusi yang dimiliki. Perpustakaan sebagai pusat dokumentasi, penyedia informasi dan penyebarluasan informasi memiliki peran primer dalam mengembangkan dan mengelola repositori intitusi yang dimiliki. Hal inilah yang mendasari peneliti untuk mencari tahu lebih jauh lagi mengenai penerapan Eprint di Perpustakaan UMM.

\section{TINJAUAN LITERATUR}

\section{a. Perpustakaan Perguruan Tinggi}

Perpustakaan perguruan tinggi merupakan Unit Pelaksana Teknis (UPT) Perguruan Tinggi yang bersama-sama dengan unit lain turut melaksanakan Tri Dharma Perguruan Tinggi dengan cara memilih, menghimpun, mengolah, merawat dan melayankan sumber informasi kepada lembaga induknya pada khususnya dan masyarakat akademis pada umumnya (Qalyubi, et al, 2007:10).

Berdasarkan Standar Nasional Indonesia (2014:2) Perpustakaan Perguruan Tinggi merupakan perpustakaan yang bertujuan untuk memenuhi kebutuhan informasi pengajar dan mahasiswa di perguruan tinggi. Sehingga dapat disimpulkan bahwa perpustakaan Perguruan Tinggi merupakan perpustakaan yang berada di bawah naungan lembaga induknya, yang bertujuan untuk memenuhi kebutuhan informasi civitas akademika serta menyebarluaskan informasi yang dimiliki.

\section{b. Perpustakaan Digital}

Terdapat banyak definisi mengenai perpustakaan digital, menurut Witten, et.al (2010), perpustakaan digital sebagai koleksi terfokus benda digital, termasuk teks, video, dan audio, bersama dengan metode untuk akses dan temu kembali, dan untuk seleksi, organisasi, dan pemeliharaan koleksi. Dalam hal ini "benda digital" (tidak hanya teks) tercermin dalam contoh di atas. Di luar audio dan video, terdapat objek 3D, simulasi, visualisasi dinamis, danvirtual reality.

Rodliya (2012) menjelaskan sebuah perpustakaan digital secara ideal seluruh koleksinya adalah dalam bentuk digital dan tidak lagi melayankan bentuk konvensional. Namun banyak juga perpustakaan yang melayankan sebagian koleksi dalam bentuk digital dengan tetap mempertahankan koleksi yang konvensional yang banyak disebut dengan perpustakaan Hibrida.

\section{c. Repositori intitusi}

Menurut lynch (2003), repositori intitusi berbasis universitas adalah satu set layanan yang ditawarkan universitas kepada anggota komunitasnya dalam pengelolaan dan penyebaran materi digital yang dibuat oleh lembaga dan anggota komunitasnya. Sementara Johnson dalam Westell (2006: 213), repositori intitusi adalah arsip digital tentang produk intelektual yang dibuat oleh pendidik, peneliti dan mahasiswa dari sebuah institusi dan dapat diakses 
oleh pengguna baik dari dalam ataupun luar institusi dengan sedikit hambatan untuk mengakses. Sedangkan Crow (2002: 4) dalam Ezema (2011: 476) menyebutkan bahwa repositori intitusi adalah menyimpan dan melestarikan koleksi digital hasil intelektual dari komunitas single atau multi-universitas dimana memberikan respon untuk dua isu strategis yang dihadapi institusi akademik. Sehingga dapat ditarik kesimpulan repositori intitusi adalah suatu set layanan yang bertujuan untuk menyimpan serta menyebarkan koleksi hasil karya sivitas akademika dalam bentuk digital agar dapat dimanfaatkan civitas akademika.

\section{d. Eprint}

Das (2015) menjelaskan Eprints diciptakan pada tahun 2000 sebagai hasil dari pertemuan 1999 Santa Fe yang dirilis yang mana pada akhirnya menjadi OAIPMH. Versi 3 dari perangkat lunak ini resmi dirilis pada tanggal 24 Januari 2007 di Konferensi Open Source Repositori 2007 yang digambarkan oleh para pengembangnya sebagai "langkah utama terdepan dalam fungsi, memberikan kontrol lebih dan fleksibilitas untuk pengelola repositori, depositor, peneliti dan administrator teknis." Lebih lanjut Sivasubramanian dan Gomathi (2016), menjelaskan beberapa fitur-fitur Eprint yaitu Accessibility via web browser, Full Text and Field Search, Administrative function, Open Source Perangkat lunak, Three-user roles(administrator, editor and author), OAI-PMH Support, Multilingual Support, File formats supported: (PDF, HTML, JPEG, TIFF, MP3, dan AVI), Statistics, Customization, Item previews in Eprints.

\section{METODOLOGI PENELITIAN}

Emzir (2014: 20) menjelaskan penelitian studi kasus adalah suatu penelitian kualitatif yang berusaha menemukan makna, menyelidiki proses, dan memperoleh pengertian dan pemahaman yang mendalam dari individu, kelompok, atau situasi. Penilitian ini dilakukan di Perpustakaan UMM dan di lembaga Infokom UMM yang berlokasi Jl. Raya Tlogomas No. 246 Malang. Pemilihan terhadap lokasi penelitian dilakukan secara purposive, yakni memilih secara sengaja dengan maksud mendapatkan sebuah lokasi yang dianggap relevan dengan tujuan penelitian.

Untuk memperoleh data yang valid dan relevan dalam penelitian ini, maka peneliti menggunakan metode pengumpulan data sebagaimana pendekatan penelitian yang digunakan yaitu observasi partisipasi pasif (passive participant), wawancara dan dokumen, Sugiyono (2014). Adapun analisis data yang digunakan dalam penelitian ini adalah analisis data model interaktif Miles (2014:12-14). Analisis data model interaktif ini memiliki empat alur yang terjadi secara bersamaan, aktivitas dalam analisis data ini antara lain pengumpulan data, kondensasi data, penyajian data dan penarikan kesimpulan.

\section{HASIL PENELITAN DAN PEMBAHASAN}

\section{a. Gambaran Umum Repositori Initusi UMM}

Perangkat lunak open-source Eprints mulai diterapkan di UMM sejak tahun 2011, setelah sebelumnya melakukan studi banding antara di Institut Teknologi Bandung (ITB) dengan membahas 
repositori intitusi Perguruan Tinggi. Keberadaan Eprints bukan berarti menggeser perangkat lunak otomasi LASER yang telah ada sebelumnya melainkan keduanya saling terintegrasi dalam perpustakaan UMM sebagai manajemen koleksi dan layanan koleksi digital.

Eprints perpustakaan UMM dikelola oleh pengembang sistem dan bagian pengelolaan konten / informasi. Pengembang Sistem dilakukan tenaga ahli dibidang IT yakni Ahmad Yusuf sebagai Web Developer pada Divisi sistem Informasi, Bidang Infokom Universitas Muhammadiyah Malang.

Selanjutnya pada bagian pengelolaan konten Eprint ditangani oleh pihak Perpustakaan UMM dibagian ELSS (Electronic Library Support Systems) yakni Faisal Harin, Afif, Bachtiar Effendy, dan Hafidz Ahyanur yang berwenang untuk memasukkan dan mengelola informasi dan juga mengelola otomasi perpustakaan. Sementara untuk koleksi yang tersedia pada Eprints UMM (http://eprints.umm.ac.id/) berisi judul dan abstrak serta deskripsi bibiliografi tugas akhir mahasiswa (skripsi dan thesis) serta karya ilmiah sivitas akademika.

\section{b. Penerapan Eprints}

Penerapan Eprint diawali inisiatif dari pihak Perpustakaan UMM dan Lembaga Infokom agar repositori intitusi UMM masuk di pemeringkatan webometric repositori perguruan tinggi dan untuk menaikkan peringkat webometric Universitas Muhammdiyah Malang dari aspek peringkat Perguruan Tinggi. Di sisi lain, Perpustakaan sebelumnya sudah mempunyai Ganesha Digital Library (GDL), namun GDL hanya bisa diakses di dalam perpustakaan dan tidak masuk dalam pemeringkatan repositori webometric, sehingga perpustakaan UMM juga menggunakan Eprint. Sampai sekarang GDL tetap dipertahankan dan tidak digabung dengan Eprint karena dari pihak Teknologi Informasi perpustakaan kesulitan untuk migrasi data dari GDL ke Eprint.

Sementara dalam pengelolaannya, Perpustakaan UMM melalui bagian Electronic Library Support Systems (ELSS) bertugas mengolah dan memasukkan konten berupa tugas akhir (skripsi, thesis, disertasi dan karya ilmiah lainya) ke dalam repositori ini. Dalam pengolahan konten di Eprint, petugas perpustakaan UMM tidak mengunakan pedoman seperti AACR2/RDA. Petugas perpustakaan UMM hanya mengisi ruasruas yang ada pada Eprint seperti judul, pengarang, abstrak dan sumber.

Sedangkan Lembaga Infokom melalui Divisi Pengembangan Sistem Informasi dan Divisi jaringan bertugas mengembangkan dan mengelola (maintanance) Eprint. Lembaga Infokom hanya bertugas mengembangkan dan mengelola Eprint, dengan kata lain Perpustakaan UMM yang mengolah dan memperbanyak kontennya.

Dalam pengembangannya, Eprint Perpustakaan UMM telah mengalami beberapa pengembangan sistem seperti modifikasi fitur akses download. Modifikasi fitur akses download yaitu dengan menambahkan opsi pengunduhan yang bisa disimpan dalam postscribe, pdf dan txt. Modifikasi semacam ini dilakukan untuk memudahkan pengguna yang ingin melakukan pengunduhan dalam format variasi yang berbeda. Selain itu, saat ini Eprint sedang proses upgrade versi dari Eprint 3.0 ke Eprint 3.3. Upgrade Eprint ini bertujuan untuk memperkuat keamanan, Eprint 3.3 memiliki sekuritas yang lebih baik 
daripada sebelumnya, selain itu penggunaan database yang seblumnya MySQL, akan berganti dengan Maria DB di Eprint 3.3.

Dengan adanya pengembangan sistem Eprint diharapkan memberikan dampak yang signifikan bagi pemustaka sehingga dapat digunakan dengan sebaikbaiknya. Beberapa dampak Eprint yaitu sebagai sarana yang memuat referensi / bahan rujukan untuk mahasiswa, dosen dan peneliti dalam menelusur informasi untuk kebutuhan studi dan riset serta memudahkan pemustaka dalam mengakses referensi yang di mana dan kapan pun. Meningkatkan Peringkat repositori UMM dan peringkat repositori webomatric terbukti UMM menduduki peringkat ke 13 sebagai ranking of web repositories se Indonesia. (http://repositories.webometrics.info/en LAsia/Indonesia, diakses 21 Mei 2017).

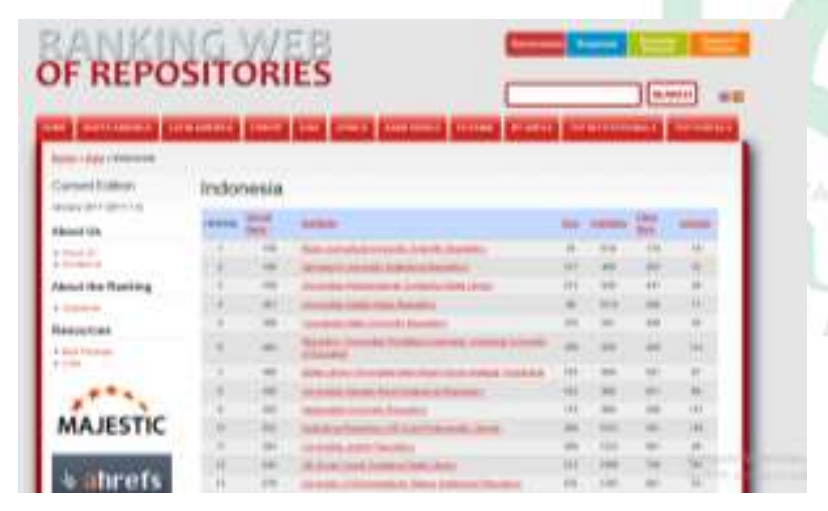

Gambar 1. Peringkat repositori institutusi Indonesia (sumber: hasil olahan peneliti 2017)

\section{c. Faktor Pendukung dan Penghambat}

Beberapa faktor yang mendukung penerapan Eprint Perpustakaan UMM adalah lembaga infokom UMM. Lembaga infokom mewadahi pengembangan Eprint perpustakaan UMM. Lembaga infokom melalui Divisi Pengembangan Sistem
Informasi dan Divisi jaringan terus berupaya mengembangkan Eprint.

Sedangkan faktor penghambat dari penerapan Eprint yaitu penanggung jawab repositori intitusi sendiri masih terlihat bias dalam pembagian tugas dan wewenang pengelolaan maupun pengembangan pada Institutional Repositoy Perpustakaan. Pelaksanaan repositori intitusi masih tumpang tindih antara Lembaga Infokom dan Perpustakaan UMM. Selain itu terdapat dualisme repositori intitusi antara Eprints dan GDL. Perpustakaan UMM sendiri secara penuh mengelola GDL namun tidak masuk dalam pemeringkatan repositori webometric, sedangkan Eprint dikembangkan oleh Lembaga Infokom UMM masuk ke dalam pemeringkatan repositori webometric.

\section{KESIMPULAN DAN IMPLIKASI PENELITIAN}

Dari hasil analisis penelitian ini dapat disimpulkan bahwa :

1) Penerapan Eprint di perpustakaan UMM bermula sejak tahun 2011. Keberadaan Eprints bukan berarti menggeser perangkat lunak otomasi LASER dan GDL yang telah ada sebelumnya. Keberadaan Eprint bertujuan untuk mendongkrak pemeringkatan repositori webometric UMM.

2) Perpustakaan UMM berperan dalam pengolahan konten yang berupa tugas akhir dan karya ilmiah sivitas akademika. Sedangkan Lembaga Infokom melalui Divisi Pengembangan Sistem Informasi dan Divisi jaringan bertugas mengembangkan, mengelola dan maintanance sistem Eprint. 
3) Faktor pendukung dalam penerapan Eprint adalah adanya lembaga infokom mewadahi pengembangan repositori intitusi. Sedangkan faktor penghambat yaitu penanggung jawab repositori intitusi sendiri masih terlihat bias dalam pembagian tugas, wewenang, pengelolaan dan pengembangan serta adanya dualisme repositori intitusi antara Eprints dan GDL

Penelitian ini berimplikasi pada:

1) Pihak UMM perlu menetapkan kebijakan yang jelas dan tertulis berkaitan dengan repositori intitusi dan pengelolaan Eprint.

2) Pihak Perpustakaan perlu menyediakan sumber daya manusia terampil yang bertugas dalam mengembangkan dan mengelola Eprint dan juga perlu mengadakan sosialisasi kepada mahasiswa terkait dengan Eprints, agar semua pemustaka mengetahui bagaimana fungsi dan penggunaan Eprints.

3) Bagi perpustakaan perguruan tinggi lain, sebaiknya lebih cermat dalam memanfaatkan repositori intitusi yang dikembangkan, sehingga tidak terjadi dualisme repositori intitusi dan tumpang tindih dalam pengelolaan repositori intitusi.

\section{DAFTAR PUSTAKA}

Das, A. K. (2015). "Comparing Open Source Digital Library Perangkat lunak : Special Reference to DSpace, Eprint and Greenstone" Dalam

https:/ /www.ijarcsse.com/docs/ papers/Volume_5/7_July2015/V5 I7-0132.pdf, diakses pada 5 Maret 2017 pukul 09.00 WIB.

Ezema, I. J. (2011). “Building Open Access Institutional

Repositories
forGlobal Visibility of Nigerian Scholarly Publication" dalam http:/ / search.proquest.com/docv iew/877019300/fulltextPDF/BB2 A338B813841BBPQ/3?accountid= 46437diakses padatanggal 21 Desember 2015 pukul 11.48 WIB dari

Emzir. (2014). Metodologi Penelitian Kualitatif: Analisis Data. Jakarta: Rajawali Pers.

Lynch, C. A. (2003). "Institutional Repositories: Essential Infrastructure for Scholarship in the Digital Age" dalam http://www.arl.org/resources/p ubs/br/br226/br226ir.shtml, diakses pada 11 maret 2017 pukul 06.00 WIB

Miles, H., dan Saldana. (2014). Qualitative Data Analysis: A Methods Sourcebook 3rd Ed.USA :Sage Publishing.

Qalyubi, S., et al. (2007). Dasar-dasar Ilmu Perpustakaan danInformasi. Yogyakarta : Jurusan Ilmu Perpustakaan dan InformasiFakultas Adab UIN Sunan Kalijaga

Randhawa, S. (2008). "Open Source Perangkat lunak and Libraries" Dalamhttp:/ / arizona.openreposit ori.com/arizona/bitstream/10150 /105743/1/Open_Source_Perang kat lunak_and_Libraries.pdf, diakses pada 06 maret 2017 pukul 17.10 WIB

Rodliyah, U. (2012). "Perpustakaan Digital, dan Prospeknya Menuju Resource Sharing." Dalam http://www.perpusnas.go.id/ma gazine/perpustakaan-digital-danprospeknya-menuju-resourcesharing/, diakses pada 06 maret 2017 pukul 17.10 WIB 
Sugiyono. (2014). Metode Penelitian Kuantitatif, Kualitatif Dan R\&D. Bandung: Alfabeta.

Sivasubrahamanian, G. \& Gomathi, P. (2016). “Open source digital library perangkat lunak 's: exceptional indication to dspace, Eprints and greenstone - an overview" Dalam http://iaset.us/download.php?fn ame $=2-89-1452771558$ -

5.\%20IJLES\%20\%20OPEN\%20SOURCE\%20DIGIT AL\%20LI.pdf, diakses pada 5 Maret 2017 pukul 10.00 WIB.

Webometric. (2017). “Peringkat webometric repositori Indonesia" dalam http:/ / repositories.webometrics.i nfo/en/Asia/Indonesia, diakses 4 Maret 2017 pukul 16.00 WIB

Westell, M. (2006). "Institutional Repositories: Proposed Indicators ofSuccess", dalam http:// search.proquest.com/docv iew/200532643/fulltextPDF/F264 CC7DBCBF412DPQ/5?accountid= 46437 diakses pada tanggal 21 Desember 2015 pukul 11.52 WIB

Witten, I. H., Banbridge., dan Nichols, D. M. (2010). How to build Digital Library: Second Edition. Burlington: Elsevier. 